\title{
Influência do cálcio e do silício, via fertirrigação, na qualidade de hastes florais de gérbera ${ }^{(1)}$
}

\author{
SUEYDE FERNANDES DE OLIVEIRA(2,3); SIMONE DA COSTA MELLO(2); KEIGO MINAM|(2)
}

\begin{abstract}
RESUMO
Com o objetivo de estudar o efeito do cálcio $(\mathrm{Ca})$ e do silício $(\mathrm{Si})$, via fertirrigação, na qualidade de flores cortadas de gérbera, foi conduzido um experimento em casa de vegetação, no delineamento experimental em blocos casualizados, em esquema de parcelas subdivididas, sendo os tratamentos constituídos por três níveis de Ca $(7,5 ; 10,0$ e 12,5 mmol.L-1) e quatro níveis de $\mathrm{Si}(0 ; 2,95 ; 4,43$ e 5,89 mmol.L-1), aplicados via solução nutritiva, avaliados em três épocas, com três repetições. O cultivo da gérbera foi feito em vasos plásticos de $5 \mathrm{~L}$, preenchidos com fibra de coco. A partir do início das aplicações, na fase reprodutiva, foram avaliados a qualidade das hastes florais no ponto de colheita, pelo comprimento e diâmetro da haste, diâmetro do capítulo e intensidade da coloração das pétalas (L, C, a, b e ho ), além da longevidade e perda de massa no período pós-colheita. A qualidade das hastes florais sofreu influência da aplicação de Ca e Si para o parâmetro a, cromaticidade e comprimento da haste, aos 90 e 150 dias após o transplante (DAT). O Si aplicado semanalmente via solução nutritiva durante o cultivo da gérbera aumentou a vida pós-colheita de flores coletadas aos 210 DAT.

Palavras-chave: Gerbera jamesonii, flor de corte, pós-colheita.
\end{abstract}

ABSTRACT

Influence of calcium and silicon fertirrigation in the quality of cut gerbera

\begin{abstract}
Aiming to evaluate the effect of $\mathrm{Ca}$ and $\mathrm{Si}$ fertirrigation in the quality of cut gerbera, was conducted one experiment in a greenhouse, in experimental design in blocks randomized, in split plot in time, being the treatments three doses of $\mathrm{Ca}(7,5$; 10 e 12,5 mmol.L-1) and four doses of $\mathrm{Si}(0 ; 2,95 ; 4,43$ and 5,89 mmol.L-1), applied nutrient solution, valued at three times, with three replication. The cultivation of gerbera was held in plastic pots $5 \mathrm{~L}$, containing coconut fiber. At the beginning of the application, in the reproductive phase, were evaluated flowering stem quality on its harvest point, evaluated by the length and diameter stem, diameter chapter and intensity of petals coloration ( $\mathrm{L}, \mathrm{C}, \mathrm{a}, \mathrm{b}$ e $\mathrm{h}^{\mathrm{o}}$ ), besides vase longevity and fresh mass loss of flowers in the postharvest period. The quality of flowering stem was influenced by $\mathrm{Ca}$ and $\mathrm{Si}$ for parameter a, chromaticity and length stem, to 150 days after transplantation (DAT). The Si applied weekly nutrient solution during the gerbera growth increased postharvest flowers collected at 210 DAT.
\end{abstract}

Keywords: Gerbera jamesonii, cut flower, postharvest.

\section{INTRODUÇÃO}

No Brasil, a produção de flores e plantas ornamentais constitui um dos segmentos produtivos agroindustriais mais promissores, sendo uma alternativa eficiente para o desenvolvimento econômico e social (NOGUEIRA JUNIOR, 2001; STRINGUETA et al., 2002).

A contínua expansão do mercado interno e das exportações de flores pelo Brasil depende do aumento da demanda dos consumidores atuais e da conquista de novos mercados, por meio da disponibilidade no mercado de produtos diferenciados. Tanto o mercado externo, como o interno, exigem flores de qualidade, tanto em estética como sanitária, e com longevidade pós-colheita adequada (JOINER et al., 1983; NOWAK e RUDNICKI, 1990). Assim, os produtores têm se preocupado com o manejo da cultura, buscando tecnologias que levem ao aumento da produtividade e da qualidade.

A qualidade de flores de corte envolve uma série de atributos, enquadrados em fatores pré-colheita, como escolha da cultivar, ambiente de cultivo, nutrição e sanidade; fatores durante a colheita, como temperatura e estádio de maturação das hastes; e fatores pós-colheita, como redução do calor de campo, beneficiamento, classificação, embalagem e armazenamento (CUQUEL et al., 2009).

Na gérbera, o manejo da solução nutritiva é fundamental para a obtenção de elevada qualidade e produtividade das flores (LUDWIG et al., 2009), sendo necessário o conhecimento das concentrações dos nutrientes e da relação entre eles (BARBOSA, 2009), para uma adubação eficiente.

$\mathrm{O}$ cálcio $(\mathrm{Ca})$ tem importante função na qualidade das flores (GISLEROD, 1999), sendo essencial para a permeabilidade das membranas e manutenção da integridade estrutural da parede celular (MALAVOLTA, 2006). O Ca liga-se à pectina da lamela média, originando o pectato de cálcio, formando uma estrutura de parede com elevada resistência mecânica (DEMATRY et al., 1984). Além disso, esse nutriente retarda a senescência de flores cortadas de gérbera (GERASOPOULOS e CHEBLI, 1999).

Aplicações de cloreto de cálcio a 1,5\%, dirigidas para as hastes florais de gérbera em desenvolvimento, aumentaram o conteúdo de Ca nesses órgãos e reduziram a ocorrência

\footnotetext{
(1) Recebido em 17/11/2011 e aceito para publicação em 26/10/2012.

${ }^{(2)}$ Departamento de Produção Vegetal, Escola Superior de Agricultura Luiz de Queiroz (ESALQ), Universidade de São Paulo (USP). Avenida Pádua Dias, n 11, 13418-900, Piracicaba (SP).

${ }^{(3)}$ Autor para correspondência: sueydefo@yahoo.com.br
} 
da curvatura (GERASOPOULOS e CHEBLI, 1999).

O silício, embora não seja considerado um elemento essencial para a nutrição das plantas, segundo a definição clássica de essencialidade, tem sido frequentemente aplicado por proporcionar diversos efeitos benéficos, como a formação de folhas eretas e com maior capacidade fotossintética, aumento no teor de clorofila em dicotiledôneas, redução na transpiração e na perda de água, aumento na resistência mecânica dos tecidos e maior resistência às doenças (EPSTEIN, 1999; MALAVOLTA, 2006).

A aplicação de $\mathrm{Si}$, principalmente em cultivos em substratos, aumenta a tolerância ao estresse hídrico e proporciona hastes florais mais grossas e com menor ocorrência de curvatura. SAVVAS et al. (2002) verificaram que a adição de $\mathrm{Si}(1,25 \mathrm{mM})$ à solução nutritiva durante o cultivo de gérbera resultou na formação de hastes florais significativamente mais grossas e no menor número de hastes com curvatura, provavelmente devido ao reforço da parede celular, pela deposição de Si.

No entanto, as informações sobre a nutrição de gérbera de corte, na literatura, ainda são escassas, principalmente a nível nacional. Assim, este trabalho teve como objetivo estudar o efeito do $\mathrm{Ca}$ e do $\mathrm{Si}$, via fertirrigação, no desenvolvimento, produção e qualidade de gérbera de corte.

\section{MATERIAL E MÉTODOS}

O experimento foi conduzido em casa de vegetação, entre 18 de novembro de 2009 a 4 de setembro de 2010, na área experimental do Departamento de Produção Vegetal, da ESALQ/USP, em Piracicaba (SP). A casa de vegetação é de estrutura metálica do tipo arco, apresentando $28 \mathrm{~m}$ de comprimento, $12,80 \mathrm{~m}$ de largura e 3,4 $\mathrm{m}$ de altura de pé direito, coberta com filme de polietileno aditivado (antiUV) com $150 \mu \mathrm{m}$ de espessura e laterais fechadas com duplo filme de polietileno aditivado (bolha). $\mathrm{Na}$ altura do pé direito, instalou-se uma cobertura com tela termorefletora aluminizada com 50\% de sombreamento, com movimentação manual. O controle da temperatura foi realizado por meio de sistema resfriativo evaporativo (Pad $\&$ Fan e nebulização), para manter a temperatura em torno de $27^{\circ} \mathrm{C}$ durante o desenvolvimento da planta.

O delineamento experimental foi em blocos casualizados, em esquema fatorial. Os tratamentos foram constituídos por três níveis de $\mathrm{Ca}(7,5 ; 10,0$ e 12,5 mmol.L $\left.\mathrm{L}^{-1}\right)$ e quatro níveis de $\mathrm{Si}(0 ; 2,95 ; 4,43$ e 5,89 mmol.L $L^{-1}$, aplicados via solução nutritiva. Os tratamentos foram avaliados em três épocas ao longo do experimento, em parcelas subdivididas no tempo, com três repetições (30 vasos por unidade experimental). A fonte de Ca foi o Librel (9,5\% Ca), nas concentrações de 300, 400 e 500 mg.L ${ }^{-1}$, e a de $\mathrm{Si}$ foi o FertiSil (12\% $\mathrm{K}_{2} \mathrm{O}$ solúvel em água - 165,6 g.L. e $^{-1}$ 12\% de Si solúvel em água - 165,6 g.L.-1), cujas concentrações foram 0,$0 ; 0,5 ; 0,75$ e 1,0 mL.L ${ }^{-1}$.

A cultivar de gérbera de corte utilizada foi a Shania ${ }^{\circledR}$. O cultivo foi realizado em vasos de plástico de coloração preta, com capacidade de 5,0 L, preenchidos com fibra de coco. Os vasos foram colocados sobre tijolos de cerâmica para permitir o escoamento da solução nutritiva drenada.
A irrigação foi feita por gotejadores autocompensados com quatro emissores (vazão de 1 L.hora ${ }^{-1}$ por emissor). As fertirrigações foram feitas diariamente com soluções nutritivas com condutividade elétrica (CE) em torno de 1,4 $\mathrm{dS} . \mathrm{m}^{-1}$. A solução nutritiva utilizada na fase vegetativa foi composta dos seguintes fertilizantes em g. $1000 \mathrm{~L}^{-1}: 820$ nitrato de $\mathrm{Ca}, 410$ nitrato de $\mathrm{K}, 164 \mathrm{MKP}, 114,8$ nitrato de $\mathrm{Mg}, 410$ sulfato de $\mathrm{Mg}, 25$ Conmicros ${ }^{\circledR}$ e 16 Libfer ${ }^{\circledR}(7 \%$ $\mathrm{Fe})$. Na fase reprodutiva, foram empregadas as quantidades dos fertilizantes em g. $1000 \mathrm{~L}^{-1}$ : 410 nitrato de K, 164 MKP, 547,5 nitrato de Mg, 228,8 nitrato de amônio, 25 Conmicros ${ }^{\circledR}$ e 16 Libfer ${ }^{\circledR}(7 \%$ Fe). Nesse período, deuse início à fase experimental, tendo sido o $\mathrm{Ca}$ foi aplicado quatro vezes por semana e o $\mathrm{Si}$, semanalmente, ambos, isoladamente.

A colheita das hastes florais foi feita semanalmente quando atingiram o ponto de comercialização, caracterizado pela presença de duas fileiras de flores tubulares completamente abertas.

Foi avaliada a qualidade comercial das flores produzidas a cada intervalo de 60 dias. No ponto de colheita, quando o capítulo apresentava duas fileiras de flores tubuladas completamente abertas (DE JONG, 1978), eram avaliados: o diâmetro do capítulo, o comprimento da haste floral, o diâmetro da haste floral e a intensidade da coloração das pétalas, através da luminosidade (L); o ângulo Hue $\left(\mathrm{h}^{\circ}\right)$; os parâmetros $a$ e $b$; e a cromaticidade (C), que representa a intensidade da cor. Neste mesmo período, para a avaliação da pós-colheita das hastes florais, cinco flores foram padronizadas quanto ao comprimento da haste floral, identificadas e pesadas. Em seguida, as hastes foram colocadas em vasos de vidro contendo $500 \mathrm{~mL}$ de uma solução com água destilada e hipoclorito de sódio, a qual foi renovada a cada três dias até o término do experimento (VAN DOORN e DE WITTE, 1994). As hastes florais foram mantidas em câmara fria a $20 \pm 1{ }^{\circ} \mathrm{C}$ e umidade relativa do ar em torno de $60-70 \%$, com fotoperíodo de 12 horas, sob lâmpadas fluorescentes $\left(15 \mu \mathrm{mol} . \mathrm{s}^{-1} \cdot \mathrm{m}^{-2}\right)$, conforme as normas internacionais de padronização para avaliação de flores cortadas (REID, 1980). Foram avaliadas a perda de massa acumulada e a longevidade das hastes, ou seja, o número de flores que ainda se encontravam no ponto de comercialização até o final do período avaliado, determinado pelo número de dias para o aparecimento dos seguintes sintomas: haste com pétalas desbotadas e/ ou escurecidas; presença de manchas e/ou doenças; haste murcha; haste muito curvada ou tombada; e haste com mais da metade dos discos florais visivelmente abertos.

Os dados obtidos foram submetidos à análise de variância (ANOVA), e as médias das doses de $\mathrm{Ca}$ e $\mathrm{Si}$ comparadas entre si pelo teste de Tukey $(\mathrm{p} \leq 0,05)$. Para o fator tempo, as médias foram submetidas à análise de regressão polinomial.

\section{RESULTADOS E DISCUSSÃO}

As Tabelas 1, 2 e 3 mostram as características qualitativas das hastes florais aos 90, 150 e 210 dias após o transplante das mudas (DAT), respectivamente, sendo que, nesse último período, todas as características não sofreram influência dos tratamentos. 
Aos 90 DAT, houve diferença significativa entre as doses de Ca para a intensidade da coloração das pétalas (a) e cromaticidade (C). O componente cromático $a$ dos capítulos, cujos valores positivos estão relacionados à intensidade da cor vermelha, foi maior com a aplicação de $400 \mathrm{mg} . \mathrm{L}^{-1} \mathrm{de} \mathrm{Ca}$, em relação à maior dose e estatisticamente semelhante à dose de $300 \mathrm{mg} . \mathrm{L}^{-1}$ de Ca. A cromaticidade teve a mesma tendência do componente cromático $a$. CHANG et al. (2010), ao estudarem a influência do manejo da adubação no crescimento e qualidade de hastes florais de antúrio, também observaram diferença para o componente cromático $a$, que foi maior com a aplicação de fertilizante de liberação controlada ou de solução nutritiva no substrato, em comparação à adição de composto orgânico de esterco bovino, folha de chá e serragem. Estes resultados mostraram que o manejo da nutrição tem influência sobre a coloração de hastes florais, cuja resposta depende da cultivar.

Aos 150 DAT, houve diferença significativa entre as doses de Si para o comprimento da haste, e a aplicação de $0,75 \mathrm{~mL} . \mathrm{L}^{-1}$ deste elemento acrescentou maior valor a essa característica em relação à maior dose de $\mathrm{Si}$, tendo sido estatisticamente semelhante às demais. $\mathrm{O}$ comprimento da haste de girassol ornamental também aumentou com a incorporação de 140 g.m ${ }^{-3}$ de silicato de potássio em relação ao controle (KAMENIDOU e CAVINS, 2008).

Para todos os períodos avaliados, o diâmetro do capítulo variou de 76,4 a 109,41 mm, faixa semelhante àquela obtida por MOTA et al. (2007), que foi de 91,28 a $110,87 \mathrm{~mm}$, e por SAVVAS et al. (2002), que esteve entre 102,1 e $104 \mathrm{~mm}$ para gérbera.

O comprimento e o diâmetro da haste variaram de 46,05 a $64,78 \mathrm{~mm}$ e de 5,89 a 7,10 $\mathrm{mm}$, respectivamente, valores superiores e semelhantes aos obtidos por SAVVAS et al. (2002), que encontraram valores de 45,2 a 48,2 mm e de 6,51 a $6,89 \mathrm{~mm}$.

A luminosidade (L) não sofreu influência das doses de $\mathrm{Ca}$ e $\mathrm{Si}$, concordando com os resultados obtidos por CHANG et al. (2010).

A avaliação pós-colheita foi feita até o início da senescência das hastes florais, sendo que, após este período, as hastes florais não poderiam ser comercializadas. De acordo com LUDWIG (2009), cultivares de gérbera de vaso chegaram aos 21 dias sem padrão de comercialização, com a totalidade das hastes florais apresentando injúrias como queimadura das pétalas, desidratação e abscisão das pétalas.

A Tabela 4 mostra os valores do número de hastes florais permanentes aos 90, 150 e 210 (DAT), tendo sido observado que não houve diferença entre os tratamentos para esta característica. O mesmo resultado foi obtido por BAAS et al. (1995) e BARBOSA et al. (2010), ao avaliarem os efeitos de soluções nutritivas com diferentes condutividades elétricas na pós-colheita de hastes florais cortadas de gérbera e de doses de $\mathrm{Ca}(1,0 ; 2,5 ; 4,0$ e 5,5 mmol.L $\mathrm{L}^{-1}$ ) no cultivo de crisântemo, cultivares Calabria e Blush Hawai, respectivamente.

Houve interação significativa entre as doses de $\mathrm{Si}$ e o período pós-colheita para permanência das flores coletadas aos 90 e 210 DAT (Figuras 1A e 1C). Aos 90 DAT, Figura 1A, o número de hastes florais permanentes foi maior com a ausência de Si e aplicação de 0,5 ml.L
${ }^{1}$ e $0,75 \mathrm{ml} . \mathrm{L}^{-1}$ desse elemento, em relação à maior dose, a partir do sexto dia de avaliação, sendo que, no final da avaliação pós-colheita, nas hastes florais do tratamento em que se aplicou $1 \mathrm{ml} . \mathrm{L}^{-1}$, houve uma redução acentuada no número de flores permanentes (3,9 flores). Aos 210 DAT, por sua vez, a redução no número de hastes florais com qualidade comercial foi maior na ausência de Si em relação aos demais tratamentos, Figura $1 \mathrm{C}$, aos nove dias após a colheita das hastes florais. As 150 DAT, houve influência somente do período pós-colheita no número de hastes florais permanentes (Figura 1B).

Segundo MA et al. (2001), os benefícios da aplicação deste elemento estão relacionados com a redução na transpiração, amenizando o déficit hídrico e aumentando a resistência aos estresses abióticos quando acumulado pelas folhas, o que explica os resultados obtidos aos 210 DAT.

A análise de variância não acusou efeito significativo entre as doses de Ca e Si, aos 90 e 210 DAT para a perda de massa. Entretanto, aos 150 DAT, houve diferença entre doses de Ca para esse parâmetro, tendo a aplicação de 400 mg. $\mathrm{L}^{-1}$ proporcionado menor perda de massa (Tabela 5).

Hastes florais de gérbera de corte das cultivares Campitano, Testarossa e Dino, pulverizadas antes da colheita com uma solução aquosa de $\mathrm{CaCl}_{2} 1,0 \%$, mergulhadas e tratadas com injeção desse mesmo fertilizante, tiveram o período pós-colheita prolongado, tendo ocorrido menor incidência de quebra da haste, quando comparadas ao controle (GERASOPOULOS e CHEBLI, 1999). O Ca é importante na manutenção da estabilidade e na resistência mecânica das paredes celulares (POOVAIAH et al., 1988), como também na prevenção da perda de massa e na manutenção da integridade da haste floral; dessa maneira, o Ca provoca diminuição na incidência de quebra da haste e aumento da longevidade das flores de corte.

SASAKI (2007) afirma que a perda de água é uma das principais causas de deterioração dos produtos hortícolas. Segundo DONEGA (2009), o aumento da vida pós-colheita pode ser obtido por práticas e tecnologias pré pós-colheita, como a nutrição equilibrada, o manuseio adequado, armazenamento rápido após a colheita, entre outras. Entre os nutrientes, o Ca é geralmente visto como agente redutor da taxa de senescência de plantas e amadurecimento de frutos (FERGUSON, 1984), mantendo a integridade das membranas e retardando a senescência (PICCHIONI et al., 1996).

Durante todos os períodos avaliados, houve diferença estatística ao longo do tempo quanto à perda de massa das hastes florais (Figura 2). Observou-se que até o terceiro dia de avaliação houve aumento de massa das hastes florais avaliadas aos 90 e 210 DAT. Resultados semelhantes também foram obtidos por CORDEIRO (2008) em flores de rosa, ao avaliar o efeito do 1-metilciclopropeno (MCP) sobre a vida de vaso dessa flor, pois constatou aumento de $5 \%$ na massa das flores no segundo dia após o tratamento. Este ganho inicial de massa está associado à absorção de água (SUZUKI et al., 2001). Após esse período, houve perda de massa até o final do período de avaliação. Aos 150 DAT, a perda de massa ocorreu desde o início do período pós-colheita até o final.

Aos doze dias, houve perda de massa acumulada de $29,74 \%, 36,29$ e $27,97 \%$ para as hastes florais coletadas 
aos 90, 150 e 210 DAT, respectivamente. Nesse momento, as hastes florais foram caracterizadas como não comerciais devido às lígulas murchas, presenças de manchas nas pétalas e leve curvatura das hastes.

\section{CONCLUSÃO}

A aplicação de Ca aumentou a intensidade da coloração das pétalas (a) aos 90 DAT e o Si aplicado aos 150 DAT aumentou o comprimento das hastes florais.

O Si aplicado semanalmente via solução nutritiva durante o cultivo da gérbera aumentou a vida pós-colheita das hastes florais coletadas aos 210 DAT.

\section{AGRADECIMENTOS}

As autoras agradecem à Fapesp, pela concessão do auxílio financeiro, e à Empresa PlantDefender, pela doação do Fertisil $®$, que contribuíram para o desenvolvimento da pesquisa.

\section{REFERÊNCIAS}

BAAS, R. et al. Yield and quality of carnation (Dianthus caryophyllus L.) and gerbera (Gerbera jamesonii L.) in a closed nutrient system as affected by sodium chloride. Scientia Horticulturae, Amsterdam, v.61, p.273-284, 1995.

BARBOSA, J.G. et al. Nutrição mineral e adubação de plantas ornamentais. Informe Agropecuário. Floricultura: tecnologias, qualidade e diversificação, Belo Horizonte, v.30, n.249, p.16-21, 2009.

BARBOSA, M.S. et al. Produtividade e longevidade de crisântemos, cultivados em hidroponia, em resposta a doses de cálcio. Ciência Agrotecnologia, Lavras, v.34, n.5, p.1205-1210, 2010 .

CHANG, K.H. et al. Effects of chemical and organic fertilizers on the growth, flower quality and nutrient uptake of Anthurium andreanum, cultivated for cut flower production. Scientia Horticulturae, Amsterdam, v.125, p. 434-441, 2010.

CORDEIRO, D.C. Efeito do 1-MCP sobre a vida de vaso de rosa Osiana. Viçosa: Universidade Federal de Viçosa, 2008, 56p. Dissertação (Mestrado em Fisiologia Vegetal).

CUQUEL, F.L.; FINGER, F.L.; LOGIS, V. Colheita e pós-colheita de flores de corte. Informe Agropecuário. Floricultura: tecnologias, qualidade e diversificação, Belo Horizonte, v.30, n.249, p. 16-21, 2009.

DE JONG, J. Dry storage and subsequent recovery of cut gerbera flowers as an aid in selection for longevity. Scientia Horticulturae, Amsterdam, v.9, p.389-397, 1978.

DEMATRY, M.; MORGAN, C.; THELLIER, M. Calcium and the cell wall. Plant, Cell and Environment, Oxford, v.7, p. 441-448, 1984.
DONEGA, M.A. Relação Ca:K e aplicação de silício na solução nutritiva para o cultivo hidropônico de coentro. Piracicaba: Escola Superior de Agricultura "Luiz de Queiroz", Universidade de São Paulo, 2009, 62 p. Dissertação (Mestrado em Fitotecnia).

EPSTEIN, E. Silicon. Annual Review of Plant Physiology and Plant Molecular Biology, Palo Alto, v.50, p.641-644, 1999.

FERGUSON, I.B. Calcium in plant senescence and fruit ripening. Plant, Cell and Environment, Oxford, v.7, p.477-489, 1984.

GERASOPOULOS, D.; CHEBLI, B. Effects of pre and postharvest calcium application on the vase life of cut gerberas. Journal of Horticultural Science and Biotechnology, Ashford, v.74, n.1, p.78-81, 1999.

GISLEROD, H.R. The role of calcium on several aspects of plant and flower quality from a floricultural perspective. Acta Horticulturae, The Hague, n.481, p.345-353, 1999.

JOINER, J.N.; POOLE, R.T.; CONOVER, C.A. Nutrition and fertilization of ornamental greenhouse crops. Horticultural Reviews, New York, v.5, p.317-398, 1983.

KAMENIDOU, N.; CAVINS, T.J. Silicon supplements affect horticultural traits of greenhouse-produced ornamental sunflowers. HortScience, Alexandria, v.43, n.1, p.236-239, 2008.

LUDWIG, F. et al. Qualidade pós-produção de cultivares de gérbera de vaso fertirrigadas com soluções nutritivas. Revista Brasileira de Horticultura Ornamental, Campinas, v.14, n.2, p.213-220, 2009.

MA, J.F.; MIYAKEY, Y.; TAKAHASHI, E. Silicon as a benefical element for crop plants. In: DATINOFF, L.E.; SNYDER, G.H.; KORNDORFER, G.H. Silicon in agriculture. Amsterdam: Elsevier Science, 2001. chap. 2, p.17-39.

MALAVOLTA, E. Manual de nutrição de plantas. Piracicaba: Livroceres, 2006. 638 p.

MOTA, P.R.D. et al. Crescimento da gérbera e produção de fitomassa seca em função de níveis de condutividade elétrica. In: $15^{\circ}$, CONGRESSO BRASILEIRO DE FLORICULTURA E PLANTAS ORNAMENTAIS, 15. 2007, Goiânia. Anais... Goiânia, 2007.

NOGUEIRA JUNIOR, S.P. Programa FloraBrasilis: base produtiva da floricultura nacional aumenta o desempenho exportador. Revista Brasileira de Horticultura Ornamental, Campinas, v.7, n.2, p.79-80, 2001.

NOWAK, J.; RUDNICKI, R.M. Postharvest handling and storage of cut flowers, florist greens, and potted plants. Portland: Timber Press, 1990. 210 p. 
PICCHIONI, G.A. et al. Calcium delays senescencerelated membrane lipid changes and increases net synthesis of membrane lipid components in shredded carrots. Postharvest Biology and Technology, Amsterdam, v.9, n.2, p.235-245, 1996.

POOVAIAH, B.W.; GLENN, G.M.; REDDY, A.S.N. Calcium and fruit softening, physiology and biochemistry. Horticultural Reviews, New York, v.10, p.107-152, 1988.

REID, M. Recommendations for standardized vase life evaluations. Acta Horticulturae, The Hague, n.113, p.171-173, 1980.

SASAKI, F.F. Noções básicas de pós-colheita, hortaliças minimamente processadas. Piracicaba: ESALQ, 2007. $32 \mathrm{p}$.

SAVVAS, D. et al. Effects of silicon and nutrient-induced salinity on yield, flower quality and nutrient uptake of gerbera grown in a closed hydroponic system. Journal Applied of Botany, v.76, n.5/6, p.153-158, 2002.

STRINGUETA, A.C.O. et al. Diagnóstico do segmento de produção da cadeia produtiva de flores e plantas ornamentais do Rio de Janeiro. Revista Brasileira de Horticultura Ornamental, Campinas, v.8, n.1/2, p.77-90, 2002.

SUZUKI, A. et al. Effects of retail hydration on water uptake and quality of 'madame delbard' roses after long term transport. Acta Horticulturae, The Hague, n.543, p.251-256, 2001.

VAN DOORN, W.G.; DE WITTE, Y. Effects of bacteria on scape bending in cut Gerbera jamesonii flowers. Journal of the American Society for Horticultural Science, Alexandria, v. 119, n.3, p. 568-571, 1994.

Tabela 1. Valores de F para o diâmetro do capítulo (DC), comprimento da haste (CH), diâmetro da haste (DH), luminosidade (L), parâmetros $a$ e $b$, cromaticidade $(\mathrm{C})$ e ângulo Hue $\left(\mathrm{h}^{\circ}\right)$ de gérbera "Shania" submetida às doses de Ca e Si, aos 90 dias após o transplante das mudas. Piracicaba (SP), 2010

Table 1. Values of $F$ to diameter chapter $(D C)$, length stem $(C H)$, diameter stem $(C H)$, lightness $(L)$, parameters a and b, chromaticity $(C)$ and Hue angle $\left(h^{\circ}\right)$ of gerbera "Shania" submitted to Ca and Si doses, to 90 days after transplantation. Piracicaba (SP), 2010

\begin{tabular}{|cccccc|} 
Características & Ca & $\begin{array}{c}\text { Teste F } \\
\text { Si }\end{array}$ & Ca x Si & Média geral & C.V. (\%) \\
\hline $\mathrm{DC}(\mathrm{mm})$ & $0,456^{\mathrm{NS}}$ & $0,391^{\mathrm{NS}}$ & $1,559^{\mathrm{NS}}$ & 108,42 & 3,94 \\
$\mathrm{CH}(\mathrm{cm})$ & $0,905^{\mathrm{NS}}$ & $0,498^{\mathrm{NS}}$ & $1,360^{\mathrm{NS}}$ & 59,38 & 4,75 \\
$\mathrm{DH}(\mathrm{mm})$ & $0,09^{\mathrm{NS}}$ & $1,055^{\mathrm{NS}}$ & $0,622^{\mathrm{NS}}$ & 6,43 & 5,48 \\
\hline $\mathrm{L}$ & $0,446^{\mathrm{NS}}$ & $0,137^{\mathrm{NS}}$ & $1,339^{\mathrm{NS}}$ & 42,11 & 1,38 \\
\hline $\mathrm{a}$ & $4,096^{*}$ & $0,298^{\mathrm{NS}}$ & $0,257^{\mathrm{NS}}$ & 44,22 & 1,18 \\
\hline $\mathrm{b}$ & $1,503^{\mathrm{NS}}$ & $0,121^{\mathrm{NS}}$ & $1,233^{\mathrm{NS}}$ & 20,94 & 3,76 \\
\hline $\mathrm{C}$ & $4,055^{*}$ & $0,296^{\mathrm{NS}}$ & $0,670^{\mathrm{NS}}$ & 48,94 & 1,37 \\
\hline $\mathrm{h}^{\circ}$ & $0,450^{\mathrm{NS}}$ & $0,060^{\mathrm{NS}}$ & $1,235^{\mathrm{NS}}$ & 25,30 & 3,06 \\
\hline
\end{tabular}

NS $=$ Não significativo a $5 \%$ de probabilidade; $*$ = significativo a $5 \%$ de probabilidade.

Tabela 2. Valores de F para o diâmetro do capítulo (DC), comprimento da haste $(\mathrm{CH})$, diâmetro da haste (DH), luminosidade (L), parâmetros $a$ e $b$, cromaticidade $(\mathrm{C})$ e ângulo Hue $\left(\mathrm{h}^{\circ}\right)$ de gérbera "Shania" submetida às doses de Ca e $\mathrm{Si}$, aos 150 dias após o transplante das mudas. Piracicaba (SP), 2010

Table 2. Values of F to diameter chapter $(\mathrm{DC})$, length stem $(\mathrm{CH})$, diameter stem $(\mathrm{CH})$, lightness $(\mathrm{L})$, color components $a$ and $b$, chromaticity $(C)$ and Hue angle $\left(h^{\circ}\right)$ of gerbera "Shania" submitted to Ca and Si doses, to 150 days after transplantation. Piracicaba (SP), 2010

\begin{tabular}{|cccccc|}
\hline Características & Ca & Teste F & Média geral & C.V. (\%) \\
\hline $\mathrm{DC}(\mathrm{mm})$ & $0,769^{\mathrm{NS}}$ & $0,904^{\mathrm{NS}}$ & $0,227^{\mathrm{NS}}$ & 80,92 & 16,03 \\
\hline $\mathrm{CH}(\mathrm{cm})$ & $0,917^{\mathrm{NS}}$ & $3,04^{*}$ & $0,977^{\mathrm{NS}}$ & 59,24 & 16,85 \\
\hline $\mathrm{DH}(\mathrm{mm})$ & $1,768^{\mathrm{NS}}$ & $0,332^{\mathrm{NS}}$ & $0,957^{\mathrm{NS}}$ & 7,01 & 3,58 \\
\hline $\mathrm{L}$ & $0,645^{\mathrm{NS}}$ & $0,339^{\mathrm{NS}}$ & $0,331^{\mathrm{NS}}$ & 41,22 & 0,98 \\
\hline $\mathrm{a}$ & $1,087^{\mathrm{NS}}$ & $0,541^{\mathrm{NS}}$ & $0,925^{\mathrm{NS}}$ & 44,70 & 1,09 \\
\hline $\mathrm{b}$ & $0,184^{\mathrm{NS}}$ & $0,252^{\mathrm{NS}}$ & $0,648^{\mathrm{NS}}$ & 20,70 & 2,96 \\
\hline $\mathrm{C}$ & $0,717^{\mathrm{NS}}$ & $0,377^{\mathrm{NS}}$ & $0,847^{\mathrm{NS}}$ & 49,27 & 1,36 \\
\hline $\mathrm{h}^{\circ}$ & $0,009^{\mathrm{NS}}$ & $0,265^{\mathrm{NS}}$ & $0,500^{\mathrm{NS}}$ & 24,82 & 1,90 \\
\hline
\end{tabular}

NS = Não significativo a $5 \%$ de probabilidade; * = significativo a $5 \%$ de probabilidade. 
Tabela 3. Valores de F para o diâmetro do capítulo (DC), comprimento da haste (CH), diâmetro da haste (DH), luminosidade $(\mathrm{L})$, parâmetros $a$ e $b$, cromaticidade $(\mathrm{C})$ e ângulo Hue $\left(\mathrm{h}^{\circ}\right)$ de gérbera "Shania" submetida às doses de Ca e $\mathrm{Si}$, aos 210 dias após o transplante das mudas. Piracicaba (SP), 2010

Table 3. Values of $F$ to diameter chapter $(\mathrm{DC})$, length stem $(\mathrm{CH})$, diameter stem $(\mathrm{CH})$, lightness $(\mathrm{L})$, color components $a$ and $b$, chromaticity $(C)$ and Hue angle $\left(h^{\circ}\right)$ of gerbera "Shania" submitted to Ca and Si doses, to 210 days after transplantation. Piracicaba (SP), 2010

\begin{tabular}{|c|c|c|c|c|c|}
\hline Características & $\mathrm{Ca}$ & $\begin{array}{c}\text { Teste F } \\
\text { Si }\end{array}$ & $\mathrm{Ca} \times \mathrm{Si}$ & Média geral & C.V. (\%) \\
\hline $\mathrm{DC}(\mathrm{mm})$ & 1,845 NS & 0,328 NS & $1,545 \mathrm{NS}$ & 92,62 & 4,59 \\
\hline $\mathrm{CH}(\mathrm{cm})$ & $1,732 \mathrm{NS}$ & $0,574 \mathrm{NS}$ & $1,235 \mathrm{NS}$ & 47,72 & 11,27 \\
\hline $\mathrm{DH}(\mathrm{mm})$ & $0,160 \mathrm{NS}$ & $0,326^{\mathrm{NS}}$ & $1,278 \mathrm{NS}$ & 6,48 & 6,40 \\
\hline L & 0,993 NS & 0,852 NS & 0,861 NS & 39,66 & 17,57 \\
\hline $\mathrm{a}$ & $0,966^{\mathrm{NS}}$ & 0,839 NS & 0,914 NS & 43,49 & 17,56 \\
\hline$b$ & $0,937^{\mathrm{NS}}$ & 0,724 NS & 0,862 NS & 21,48 & 18,28 \\
\hline $\mathrm{C}$ & $0,986^{\mathrm{NS}}$ & 0,792 NS & $0,926^{\mathrm{NS}}$ & 48,52 & 17,60 \\
\hline$h^{\circ}$ & 1,024 NS & 0,939 NS & 0,953 NS & 25,46 & 17,56 \\
\hline
\end{tabular}

Tabela 4. Valores de F para o número de flores permanentes coletadas aos 90, 150 e 210 DAT de gérbera "Shania" submetida a doses de cálcio e silício. Piracicaba (SP), 2010

Table 4. Values of $F$ to flowers longevity to 90, 150 e 210 DAT of gerbera "Shania" submitted to Ca and Si doses. Piracicaba (SP), 2010

\begin{tabular}{cccccc} 
DAT & Ca & Teste F & Média geral & C.V. (\%) \\
& Ca x Si & Si & $0,59^{\mathrm{NS}}$ & 4,80 & 16,80 \\
\hline 0 & $0,33^{\mathrm{NS}}$ & $3,03^{\mathrm{NS}}$ & $0,39^{\mathrm{NS}}$ & 4,87 & 9,32 \\
\hline 150 & $0,30^{\mathrm{NS}}$ & $0,49^{\mathrm{NS}}$ & $0,75^{\mathrm{NS}}$ & 4,89 & 7,59 \\
\hline
\end{tabular}

NS= Não significativo a $5 \%$ de probabilidade.

Tabela 5. Valores de F para perda de massa de flores coletadas aos 90, 150 e 210 DAT de gérbera "Shania" submetida a doses de cálcio e silício. Piracicaba (SP), 2010

Table 5. Values of F to mass loss of flowers to 90, 150 e 210 DAT of gerbera "Shania" submitted to Ca and Si doses. Piracicaba (SP), 2010

\begin{tabular}{cccccc} 
& & Teste F & & Média geral \\
DAT & Ca & Si & Ca x Si & C.V. (\%) \\
\hline 90 & $0,63^{\mathrm{NS}}$ & $0,11^{\mathrm{NS}}$ & $1,61^{\mathrm{NS}}$ & 30,00 & 15,40 \\
150 & $4,29^{*}$ & $0,78^{\mathrm{NS}}$ & $1,43^{\mathrm{NS}}$ & 24,65 & 21,12 \\
\hline 210 & $1,21^{\mathrm{NS}}$ & $0,30^{\mathrm{NS}}$ & $1,64^{\mathrm{NS}}$ & 21,61 & 23,83 \\
\hline
\end{tabular}

NS= Não significativo a 5\% de probabilidade; *= Significativo a 5\% de probabilidade. 

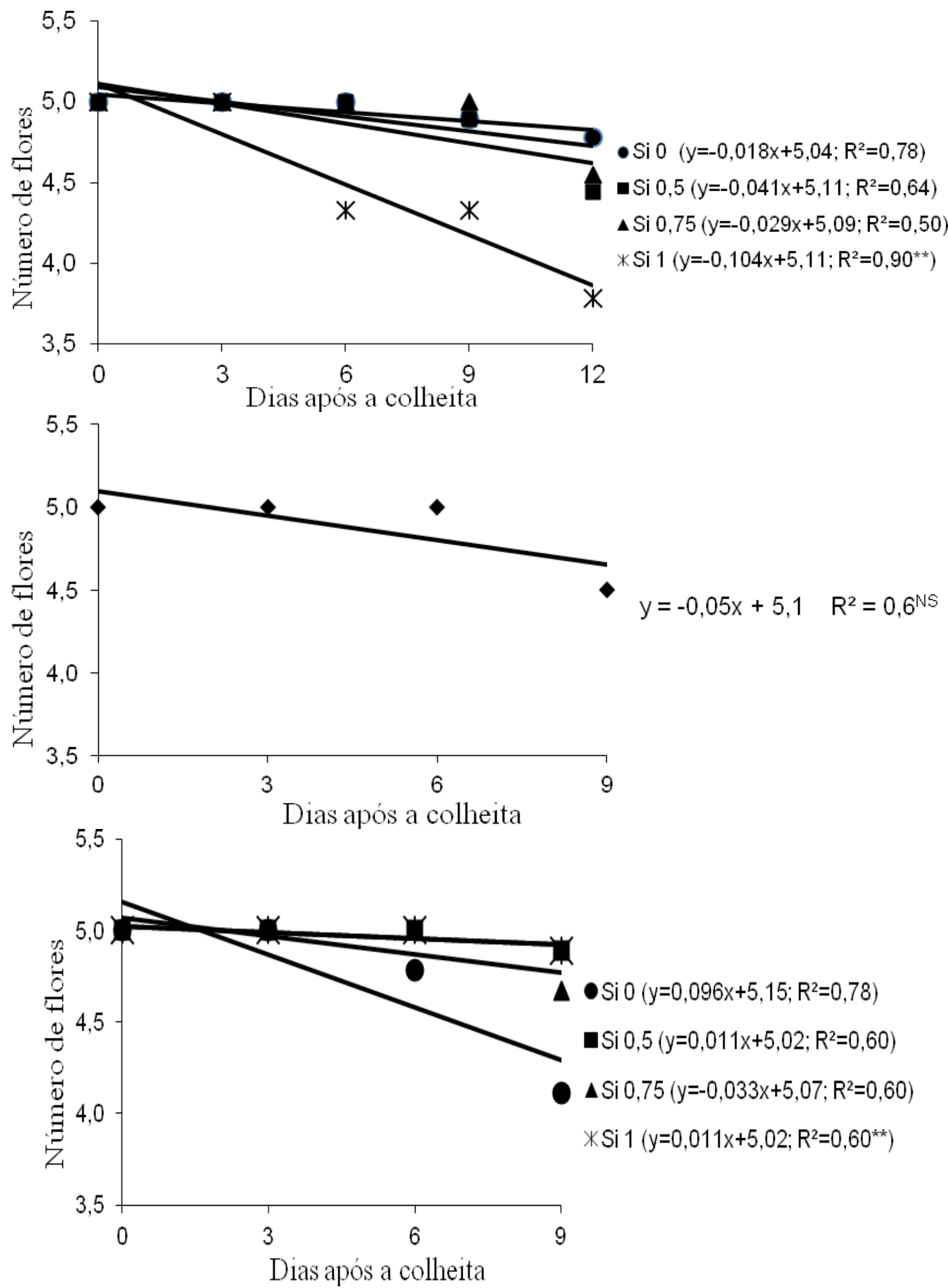

Figura 1. Número de flores de gérbera 'Shania' aos 90 DAT (1A), 150 DAT ( 1B) e 210 DAT ( 1C) em função dos dias de avaliação pós-colheita. Piracicaba (SP), 2010.

Figure 1. Number of flowers of gerbera 'Shania' to 90 DAT (1A), 150 DAT (1B) e 210 DAT (1C) according days post-harvest evaluation. Piracicaba (SP), 2010. 


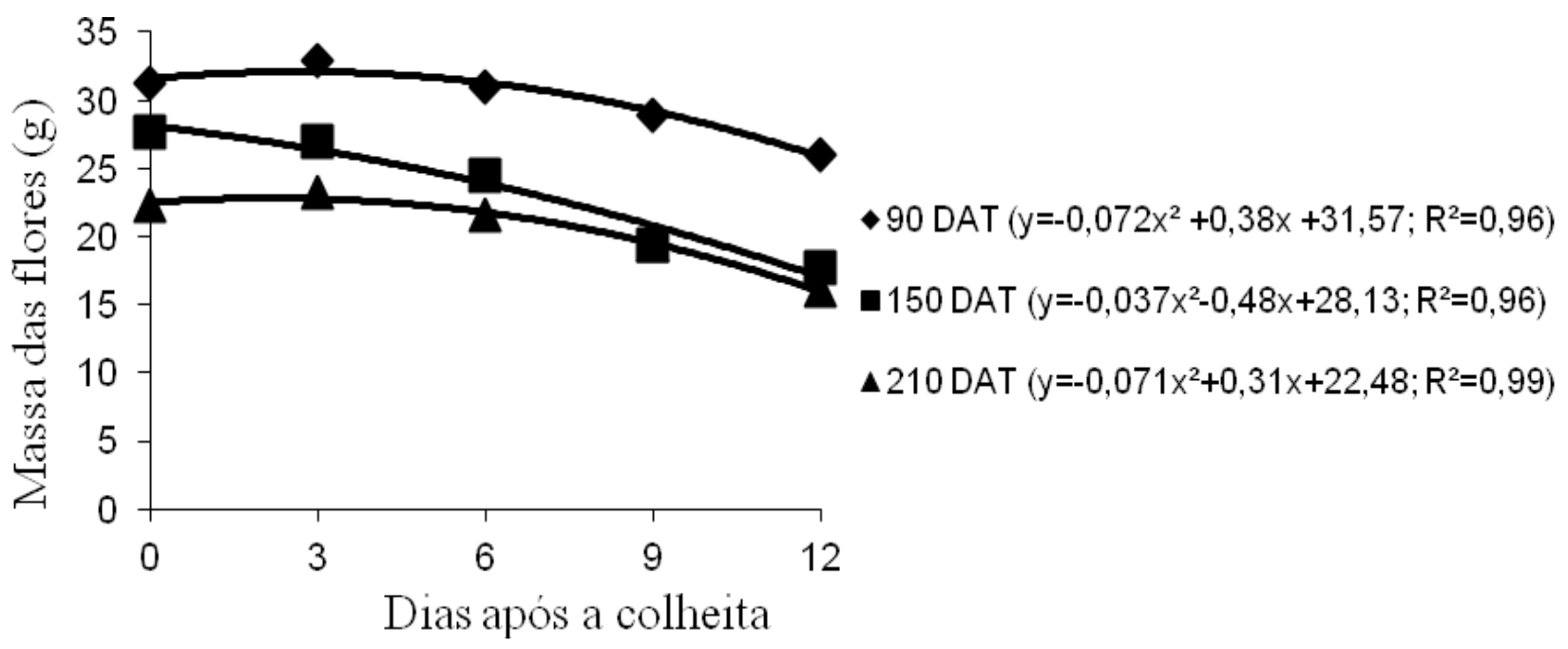

Figura 2. Massa das flores de gérbera 'Shania' aos 90, 150 e 210 DAT em função dos dias de avaliação póscolheita. Piracicaba (SP), 2010.

Figure 2. Mass of flowers of gerbera 'Shania' to 90 DAT, 150 DAT e 210 DAT according days post-harvest evaluation. Piracicaba (SP), 2010. 